\title{
ANALISIS RANCANGAN ONLINE MARKET SYSTEM PASAR TANAH ABANG ( STUDI KASUS BLOK F)
}

\author{
Aulia Paramita ${ }^{1}$, Alusyanti Primawati ${ }^{2}$, Lukman $^{3}$ \\ Program Studi Informatika, Universitas Indraprasta PGRI ${ }^{1,2,3}$ \\ aulia.pps@gmail.com¹, alus.unindra23@gmail.com², 1kmnaja51@gmail.com³
}

\begin{abstract}
Abstrak
Pengguna teknologi yang berkembang pesat bermunculan seiring dengan munculnya banyak jenis smartphone yang menjadi media komunikasi berbasis mobile dan intenet. Selain itu dengan adanya internet dan ICT proses pemasaran dan penjualan dapat dilakukan kapan saja tanpa terikat ruang dan waktu. Pasar Tradisional Tanah Abang merupakan salah satu Pasar terbesar di Asia Tenggara sehingga aktifitas bisnis dalam pasar terlihat rumit. Banyak para pedagang dari dalam atau luar Jakarta yang datang ke Pasar Tanah Abang untuk memasok produk dagangnya. Oleh sebab itu untuk mempermudah pembeli dalam berbelanja dengan menghemat ongkos dan diharapkan dapat mengurangi kepadatan/ kemacetan kendaraan maka dilakukan penelitian untuk merancang online market system pada Pasar Tanah Abang yaitu tenabangmarket.com. Metode Grounded Research digunakan untuk memperoleh konsep pemodelan sistem yang efektif. Sedangkan rancangan sistem menggunakan Unified Modeling Language (UML). Hasil yang dicapai pada penelitian ini adalah analisis sistem e-commerce berbentuk Online Market System bagi pedagang dan pembeli di Pasar Tanah Abang khususnya Blok F untuk dikembangkan selanjutnya ke tahap perancangan aplikasi.
\end{abstract}

Kata Kunci :Tanah Abang, Grounded Research, Online Market System, UML, E-Commerce.

\begin{abstract}
Technology users that is growing rapidly in line with the emergence of various kinds of smartphones as the mobile- and internet-based medium of communication. With the presence of the Internet and ICT, the marketing and selling processes can be conducted anytime and anywhere. Tanah Abang traditional market is one of the biggest Southeast Asian markets with complicated business activities. Many traders from inside or outside Jakarta come to the market to supply their products. Therefore, to help buyers shop by lowering their fares and to reduce traffic congestion, it is necessary to perform a research to design an online market system at Tanah Abang market, namely tenabangmarket.com. The concept of an effective modeling system is formulated by applying Grounded Research method, while the system itself is designed by using Unified Modeling Language (UML). The expected result of the research is an e-commerce system analysis in the form of online market system for traders and buyers at Tanah Abang Market, especially block $F$, to be next developed into the application design phase.
\end{abstract}

Keywords :Tanah Abang, Grounded Research, Online Market System, UML, E-Commerce.

A. Latar Belakang

\section{PENDAHULUAN}

Perkembangan e-Commerce dalam persaingan bisnis atau dunia perdagangan bukanlah yang dapat diabaikan begitu saja. Terjadinya persaingan untuk meningkatkan kinerja bisnis. Strategi Bersaing salah satunya adalah A-Low Cost Provider Strategy yaitu dengan melakukan Revamping The Value Chain yang merupakan penemuan cara inovatif untuk restruktuisasi proses atau tugas dapat menghemat biaya. Pasar Tanah Abang di DKI Jakarta merupakan salah satu asset ekonomi terbesar di Indonesia. Banyak pedagang yang melakukan bisnis penjualannya di dalam Pasar Tanah Abang sehingga Tanah Abang dapat disebut sebagai pusat sirkulasi jalur perdagangan di Indonesia. Pasar Tanah Abang merupakan Pasar Regional yang dikelola oleh PD Pasar Jaya. Oleh sebab itu Pasar Tanah Abang mampu melayani transaksi besar baik antar propinsi ataupun Asia 
Tenggara. Maka lokasi Pasar Tanah Abang merupakan tempat yang sangat ramai karena pedagang dan pengunjung ataupun pembeli yang berasal dari berbagai daerah. Adanya kemudahan akses di kawasan Tanah Abang dan berbagai penginapan disekitar lokasi pasar juga menjadi salah satu penyebab keramaian. Keramaian ini memunculkan banyak pedagang kaki lima di sekitar jalan Tanah Abang. Hal ini mengakibatkan kesan tidak teratur disekitar jalan raya menuju Tanah Abang ataupun jalan raya keluar dari Tanah Abang. Oleh sebab itu sering kali lokasi ini terjadi kemacetan.

Kemacetan di kawasan Tanah Abang dapat diatasi dengan memanfaatkan perkembangan teknologi internet yaitu dengan membangun sistem online market menggunakan internet commerce. Pengguna teknologi yang berkembang pesat bermunculan seiring dengan munculnya banyak jenis smartphone yang menjadi media komunikasi berbasis mobile dan internet. Selain itu dengan adanya internet dan ICT proses pemasaran dan penjualan dapat dilakukan kapan saja tanpa terikat ruang dan waktu[1].

Perkembangan teknologi internet saat ini menciptakan sebuah peluang besar dalam pertumbuhan ekonomi. Salah satunya adalah lahirnya sistem $E$ Commerce (Electronic Commerce). Dengan demikian proses jual beli dapat berlangsung dengan mudah dan cepat. Bermula dari munculnya Forum Jual Beli Online seperti tokobagus.com (sekarang olx.com), bukalapak.com, tokopedia.com, dan lainnya. Selanjutnya peranan Jejaring Sosial seperti Facebook, Instagram, Twitter yang beralih fungsi sebagai media pemasaran sebuah produk[2]. Selain itu tidak hanya Jejaring Sosial yang dimanfaatkan tetapi juga layanan Instan Messanger seperti BBM, Whats App, Line, dan lainnya sebagai alat komunikasi antara penjual dan pembeli.
Permasalahan dalam penelitian ini dirumuskan yaitu bagaimana merancang sistem online market pada Pasar Tanah Abang yang efektif khususnya pada Blok F sehingga transaksi penjualan secara online dapat memudahkan konsumen yang berasal dari luar daerah tanpa harus datang ke Pasar Tanah Abang?

Penelitian yang memiliki objek Pasar Tanah Abang ini bertujuan untuk :

1) Memudahkan pembeli/ konsumen yang berasal dari luar daerah untuk melakukan pembelian tanpa harus datang ke pasar.

2) Mengendalikan keramaian pasar sehingga dapat meningkatkan keamanan pengunjung pasar Tanah Abang.

3) Meningkatkan kompetensi pedagang menjadi Smart Seller yang dapat menjalankan Smart Business dalam memanfaatkan teknologi Smartphone

4) Diharapkan dapat mengurangi kemacetan di lokasi Pasar Tanah Abang.

Selanjutnya diharapkan keluaran yang dihasilkan sebuah Online Market System berbasis Web yang dapat berperan lebih efektif pada proses transaksi jual beli Pasar Tanah Abang. Dan diharapkan juga dapat berperan sebagai media promosi yang mampu meningkatkan volume penjualan. Dengan demikian diharapkan akan tercipta 4S yaitu Smart Seller, Smart Business, Smart User Phone, dan Smart Consumer. Dimungkinkan jika 4S ini mulai terbentuk maka penerapan Smart City akan terealisasikan dengan baik.

\section{B. Tinjauan Pustaka}

Menurut Saragih \& Ramdhany[2], eCommerce merupakan konsep dagang berupa prosedur dan mekanisme jual-beli yang terdapat pada internet. Manfaat menggunakan e-commerce adalah untuk media promosi dengan keuntungan dapat meningkatkan volume penjualan, baik untuk penjualan online maupun 
konvensional. Sedangkan Internet Marketing adalah Proses pembentukan dan pemeliharaan hubungan dengan konsumen melalui kegiatan-kegiatan online dengan memfasilitasi pertukaran ide, produk, dan jasa yang memuaskan kedua pihak[3].

Dalam menerapkan e-commerce ataupun e-marketing, ada beberapa hal yang perlu diperhatikan apabila website atau situs took online ingin mempertahankan pelanggannya. Karena tidak hanya sekedar membuat system akan tetapi perlu adanya upaya mempertahankan system dengan meningkatnya minat berbelanja kembali kepada situs tersebut. Menurut Jiang dan Rosebloom[4], indicator tersebut adalah harga dan kepuasan pelanggan saat melakukan dan setelah melakukan pembelian.Sedangkan menurut Jia Shen [5], faktor kepercayaan juga berpengaruh terhadap intensi seseorang untuk berbelanja kembali pada suatu toko online. Selain itu Saragih \& Ramdhany[2] juga menjelaskan hal yang sama tentang pentingnya kepuasaan dan kepercayaan pelanggan saat berbelanja online sehingga menarik minat dan menimbulkan intensitas pelanggan untuk berbelanja kembali di tempat online yang sama karena ketika pelanggan sudah merasakan kenyamanan dan kepuasan saat belanja online maka akan menutupi persepsi harga yang ditawarkan sehingga mengimbangi rasa aman saat berbelanja online.

M-Commerce (Mobile Commerce) memiliki lima nilai penting yaitu penyajian yang lebih fleksibel karena menggunakan perangkat mobile, kemudahan terkoneksi internet, waktu yang lebih efisien (hemat dan cepat), dapat meningkatkan produktivitas setiap proses dan transaksi, dan menyajikan transparansi yang lebih baik antara pihak penjual dan pembeli.

Peranan E-Commerce dan $M$ Commerce dalam membangun Smart City pada bidang ekonomi merupakan capaian terbesar, peranan tersebut meliputi:
1) Membantu menciptakan para wirausahawan yang menggunakan teknologi informasi (Thechnoprener).

2) Terciptakan banyak wirausahawan diharapkan dapat meningkatkan jumlah lapangan kerja.

3) Membantu pertumbuhan ekonomi daerah.

4) Mendorong kolaborasi teknologi baru lainnya.

Penelitian yang relevan terkait diantaranya:

a) Hasanah dan Sukadi [6]menulis artikel tentang Perancangan Sistem Informasi Penjualan Online Pada Toko Kreatif Suncom Pacitan sebagai solusi memecahkan masalah pada Toko Kreatif Suncom Pacitan yang masih menggunakan sistem informasi bersifat konvensional sehingga mengakibatkan kurang luasnya area pemasaran.

b) Meida dan Jauhari [7] melakukan penelitian tentang Aplikasi MCommerce untuk Penjualan Buku Pada Suatu Toko Buku Berbasis WAP (Wireless Aplication Protocol) Service dengan Media Handphone. Metode yang digunakan adalah FAST (Framework for the Aplication of System Technique dengan pendekatan Prototyping).

c) Jauhari[8] melakukan penelitian tentang Upaya Pengembangan Usaha Kecil dan Menengah (UKM) dengan memanfaatkan e-Commerce.

Dijelaskan bahwa UKM di Indonesia menghadapi masalah antara lain promosi, pemasaran dan penjualan produk. Oleh sebab itu perkembangan teknologi informasi dan komunikasi dapat memecahkan permasalahan ini dengan penerapan e-Commerce dalam UKM.

\section{METODE PENELITIAN}

Penelitian ini menggunakan Grounded Research dan salah satu cara pendekatan 
merancang sistem adalah UML (Unified Modeling Language)[9].

Pengumpulan data untuk menentukan kebutuhan-kebutuhan Sistem yang akan dirancang adalah Observasi dan Dokumentasi. Obeservasi langsung dilakukan untuk memperoleh entitas/ objek yang diperlukan dalam perancangan model sistem. Pasar Tanah Abang Blok F merupakan Objek dari penelitian ini. Pasar Tanah Abang sangat besar sehingga tidak hanya dihuni oleh pedagang dalam satu Blok Gedung melainkan terdiri dari 7 Blok yaitu Blok A sampaidengan Blok G. Akan tetapi untuk merancang Online Market System, peneliti menggunakan Blok F sebagai sampel dalam penelitian.

\section{HASIL DAN PEMBAHASAN}

A. Skenario Online Market System Pasar Tanah Abang Blok F

Dibutuhkan analisis kebutuhan melalui skenario sistem[9].

Skenario Online Market System Pasar Tanah Abang Blok F, diantaranya yaitu:

1) Tenant (Penjual Resmi Blok F Pasar Tanah Abang) melakukan registrasi ke admin sistem Tenabangmarket.com sebagai Seller terdaftar.

2) Proses Registrasi Akun Seller diantaranya: Input Nama toko yang disewa di Blok F Selanjutnya Sebagai username, Input Alamat toko, Input nama pemilik toko, Input Definisi Toko, dan Input Email Seller/ Toko.

3) Admin Validasi Akun Seller Tenabangmarket.com.

4) Proses Validasi Akun Seller diantaranya : Admin verifikasi keberadaan tenant dari data tenant di Pasar Tanah Abang Blok F3, jika tenant resmi Blok F3 maka registrasi diterima, jika bukan tenant maka registrasi ditolak, admin mengirimkan
Akun Seller ke email seller yang didaftarkan saat registrasi.

5) Seller mulai Kelola Toko di Tenabangmarket.com.

6) Proses Kelola Toko, diantaranya : Input Data Produk (Nama Produk, Gambar Produk, Jumlah Barang, Harga Satuan untuk pembelian dibawah 1 Grosir dan Harga Grosir untuk Pembelian minimal 1 Grosir), dan Input Nomor Rekening Toko/ Seller.

7) Calon Pembeli melakukan Registrasi di Tenabangmarket.com sebagai Konsumen terdaftar.

8) Proses Registrasi Akun Konsumen diantaranya: Input Username, Input Password, Input Nama Lengkap, Input Email yang aktif, Input NIK, Input Alamat Pengiriman, Input Nomor Handphone.

9) Admin Validasi Akun Konsumen Tenabangmarket.com.

10) Proses Validasi Akun Konsumen yaitu Sistem mengirimkan Link Aktifasi ke email Konsumen yang didaftarkan.

11) Konsumen membuka email Aktifasi Akun dari sistem Tenabangmarket.com dan membuka Link Aktifasi untuk mulai aktif masuk ke dalam Tenabangmarket.com

12) Konsumen Tenabangmarket.com wajib melengkapi profil, khusus menambahkan Foto Konsumen.

13) Konsumen yang sudah terdaftar memiliki Hak Akses untuk melakukan Pemesanan/ Pembelian di Tenant yang terdaftar dalam Tenabangmarket.com.

14) Konsumen mulai melakukan Transaksi Pembelian dengan mengajukan pemesanan barang yang sudah dipilih dan memasukkan jumlah barang yang akan dibeli.

15) Sistem akan mengirimkan jumlah Total Bayar dan nomor rekening Tenabangmarket.com. 
16) Konsumen dalam waktu $1 \times 6$ jam wajib menyelesaikan pembayaran. Konsumen melakukan pembayaran dengan memilih metode pembayaran dan mendaftarkan nomor rekening Konsumen.

17) Admin Tenabangmarket.com melakukan verifikasi pembayaran yang masuk rekening Tenabangmarket.com dengan mengirimkan Invoice ke Pembeli.

18) Konsumen menerima Invoice dari Sistem Tenabangmarket.com.

19) Sistem Tenabangmarket.com mengirim Invoice ke Seller untuk selanjutnya diproses oleh Seller.

20) Seller diminta untuk melakukan Validasi Penerimaan atau Penolakan transaksi pembelian.

21) Validasi Penolakan dapat dilakukan jika Seller sedang Stock Opname dan atau Seller sedang Tutup Toko.

22) Konsumen yang telah diterima prosesnya oleh Seller akan dikirimkan informasi Proses Pengiriman Barang. Konsumen yang telah ditolak prosesnya oleh Seller akan dilakukan Pengembalian biaya pembayarannya ke nomor rekening yang terdaftar dalam waktu 1 x 2 jam.

23) Seller wajib memproses Invoice yang sudah diterima selama $1 \times 48$ jam.

24) Setiap jam 4 sore Seller wajib membawa barang yang sudah dibeli dan dipacking rapih serta dilengkapi nama pembeli, alamat pengiriman dan nomor invoice ke Kantor Manajemen Tenabangmarket.com bagian Ekspedisi untuk memulai pengiriman barang yang dilakukan manajemen Tenabangmarket.com.

25) Bagian Ekspedisi Tenabangmarket.com memproses pengiriman dan mengirimkan konfirmasi pengiriman setiap invoce berupa Resi Ekspedisi ke
Admin Tenabangmarket.com untuk diinput ke sistem Tenabangmarket.com dan memperbaharui status transaksi di Tenabangmarket.com ke Seller dan Konsumen.

26) Konsumen yang sudah menerima barang pembelian wajib melakukan konfirmasi penerimaan barang untuk dikirim ke sistem Tenabangmarket.com. Jika semua barang diterima tidak ada Komplain dan Transaksi berstatus selesai. Jika Transaksi berstatus selesai maka sistem akan transfer dana penjualan ke Seller.

27) Konsumen dapat melakukan Komplain kepada sistem Tenabangmarket.com jika jumlah barang dan jenis barang yang dikirim tidak sesuai.

28) Konsumen dan Seller wajib mengirimkan ulasan transaksi sehingga Manajemen Tenabangmarket.com dapat mengevalusai Seller yang terdaftar..

29) Komplain pembelian diselesaikan antar Seller dengan Konsumen melalui Chat Komplain yang disediakan.

30) Seller dan Konsumen dapat melakukan penyelesaian Komplain dengan 2 cara: Retur Barang semua (biaya ekspedisi retur barang ditanggung pembeli dan diatur sistem Tenabangmarket.com) dan Pengembalian Biaya Beli (Kecuali biaya ekspedisi tidak ada pengembalian), Retur Barang sebagian yang tidak sesuai dan Seller wajib mengirim ulang barang yang benar (Biaya Ekspedisi dilakukan dengan sistem Tenabangmarket.com).

\section{B. Use Case Diagram}

Berdasarkan skenario sistem maka dirancang use case diagram untuk Online Market System Pasar Tanah Abang Blok F. 


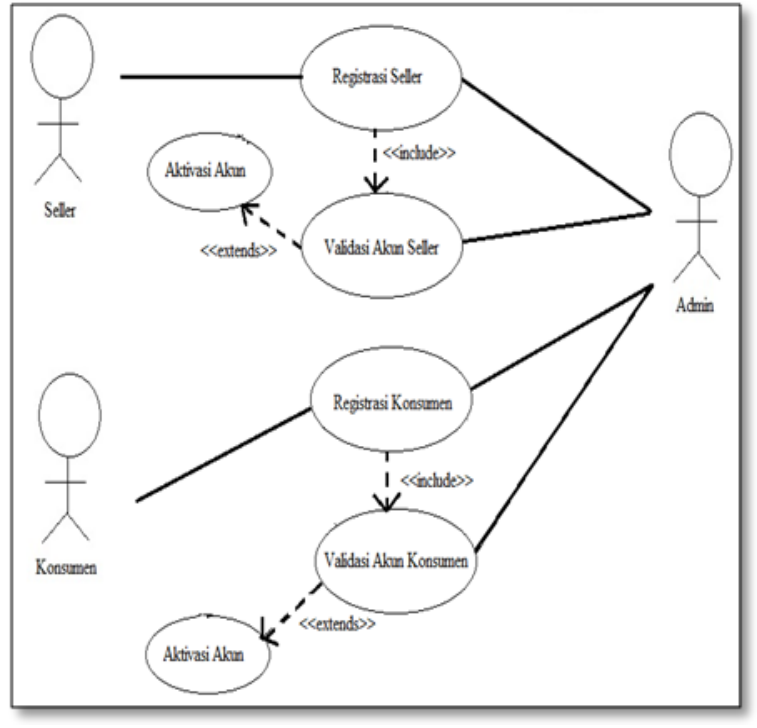

Gambar 1. Use Case Diagram Registrasi

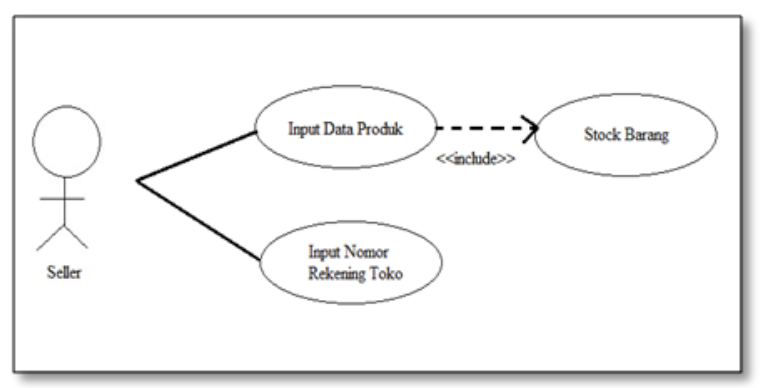

Gambar 2. Use Case Diagram Kelola Toko

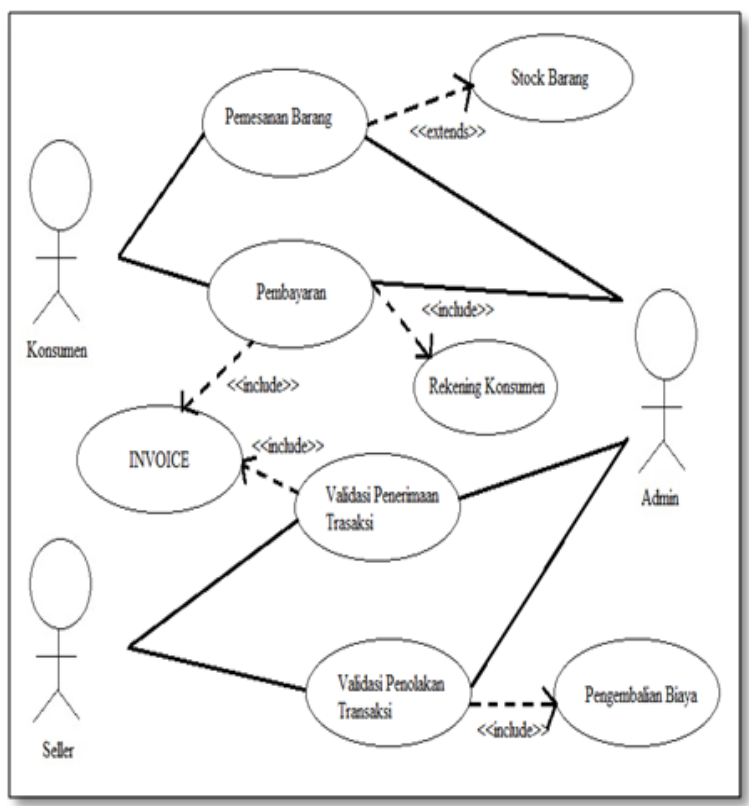

Gambar 3. Use Case Diagram Transaksi Pembelian

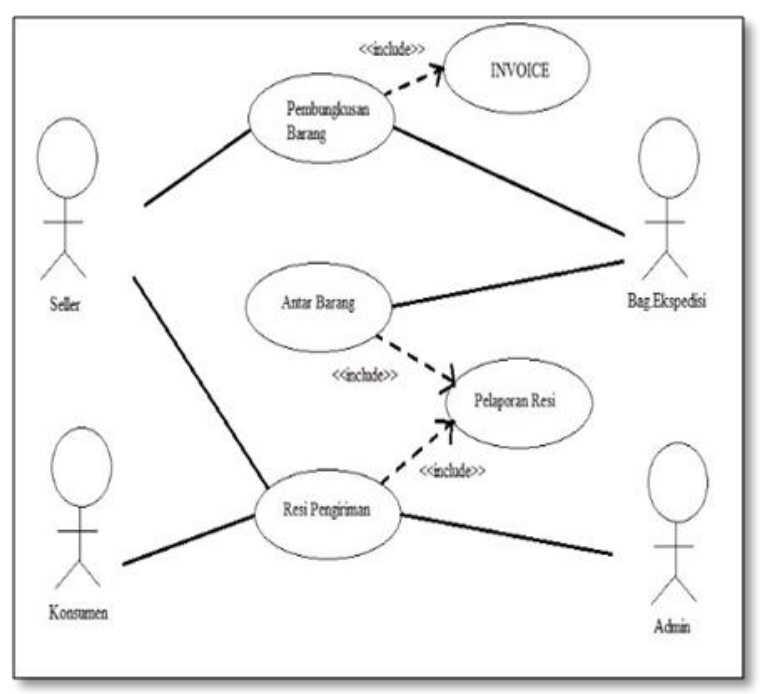

Gambar 4. Use Case Diagram Pengiriman Barang

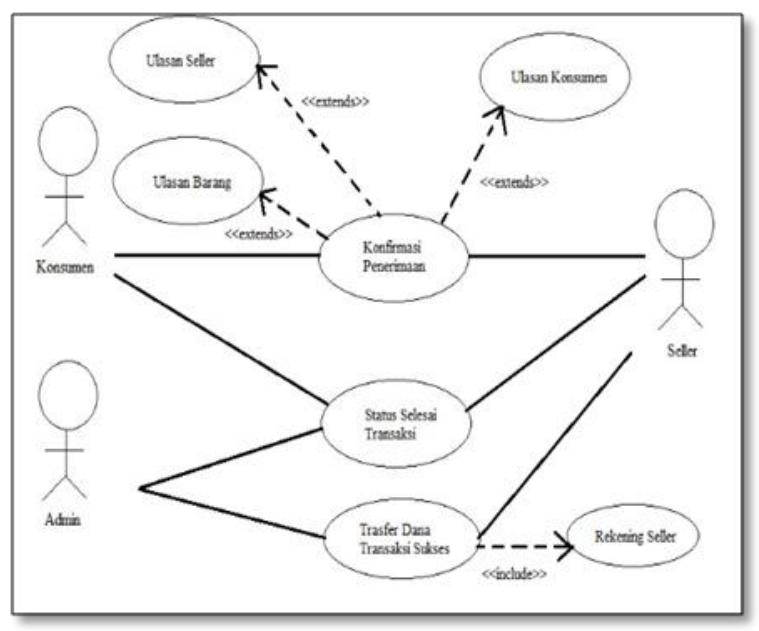

Gambar 5. Use Case Diagram Penerimaan Barang.

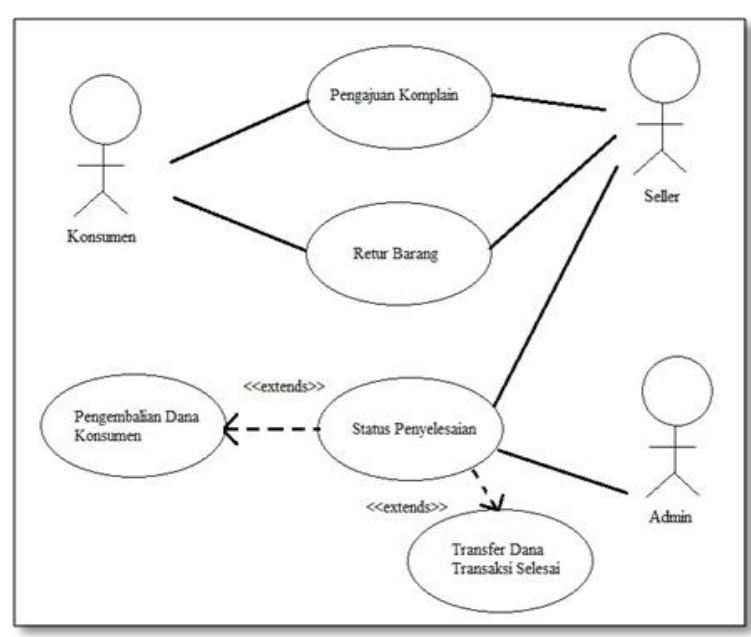

Gambar 6. Use Case Diagram Komplain 


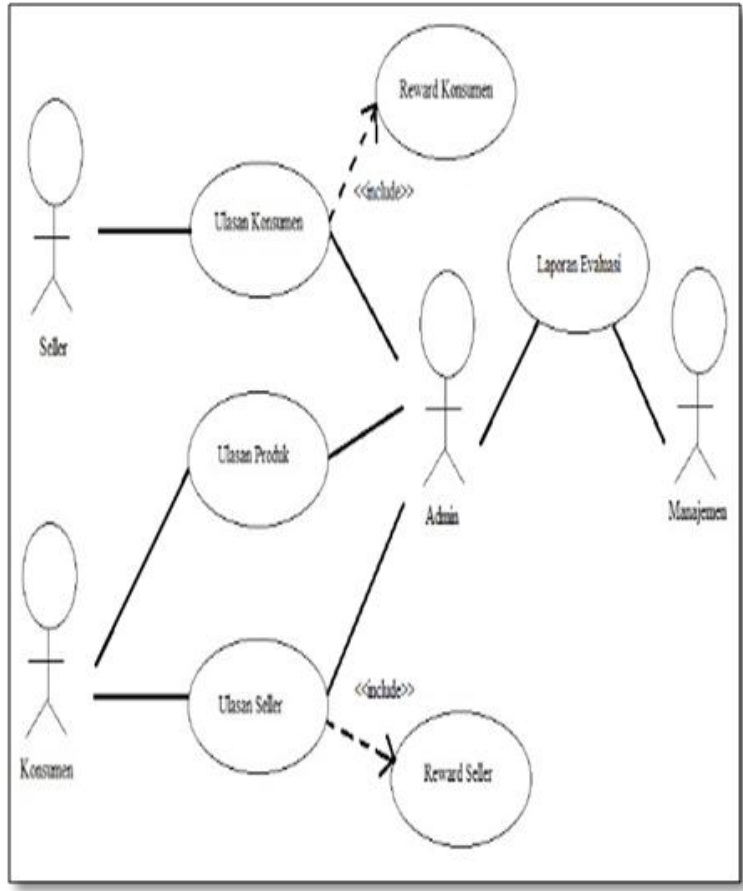

Gambar 7. Use Case Diagram Ulasan

C. Activity Diagram

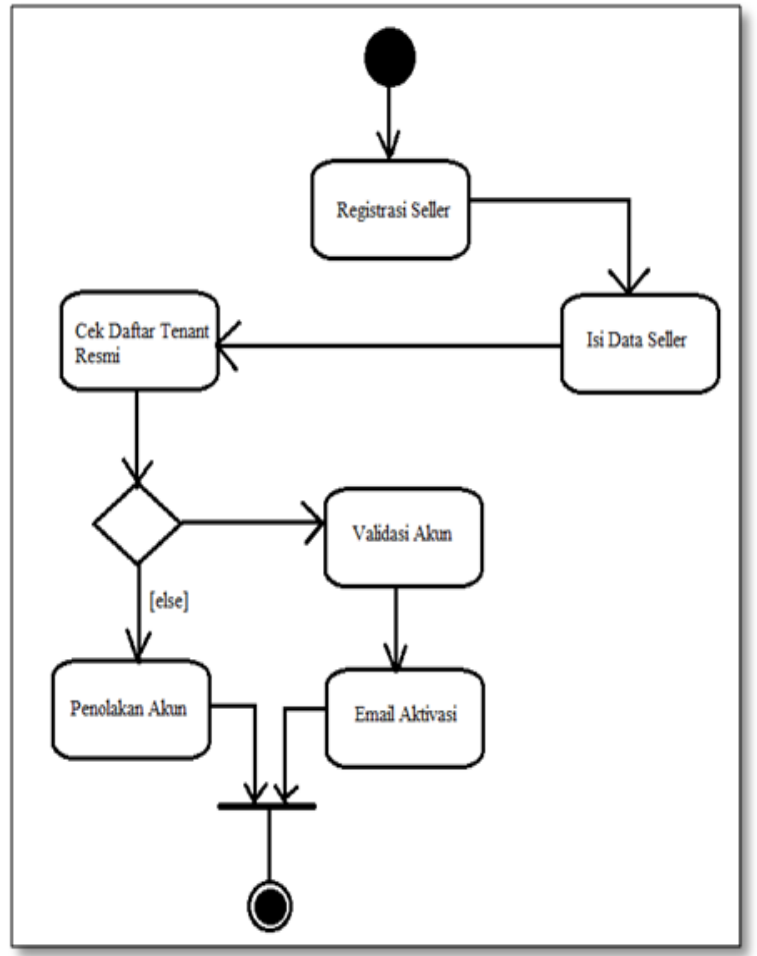

Gambar 8. Activity Diagram Registrasi Seller

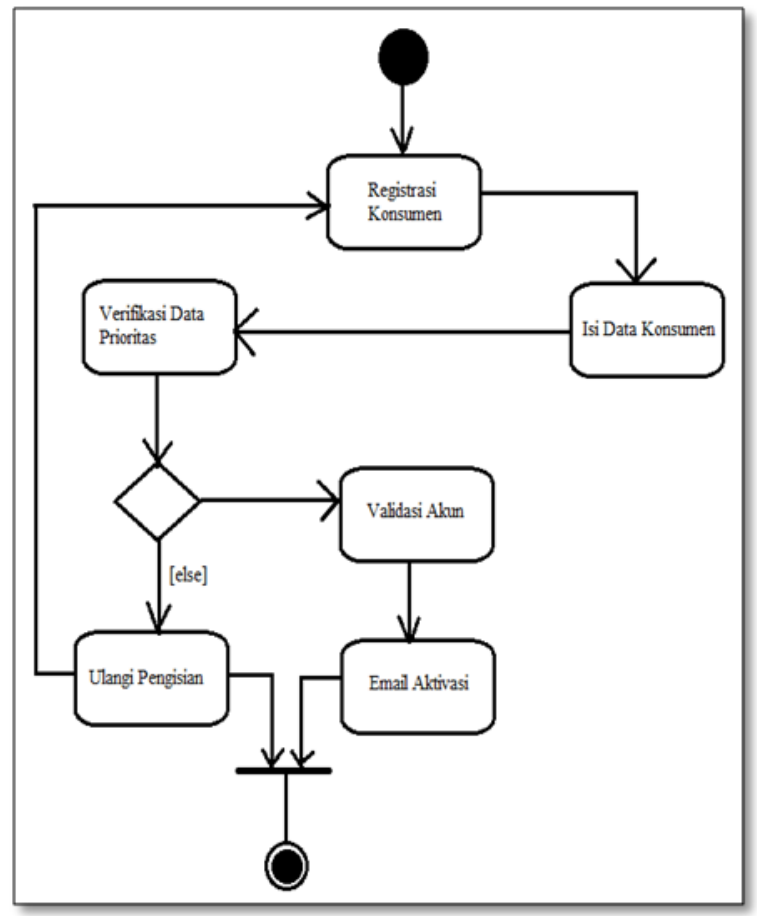

Gambar 9. Activity Diagram Registrasi Konsumen

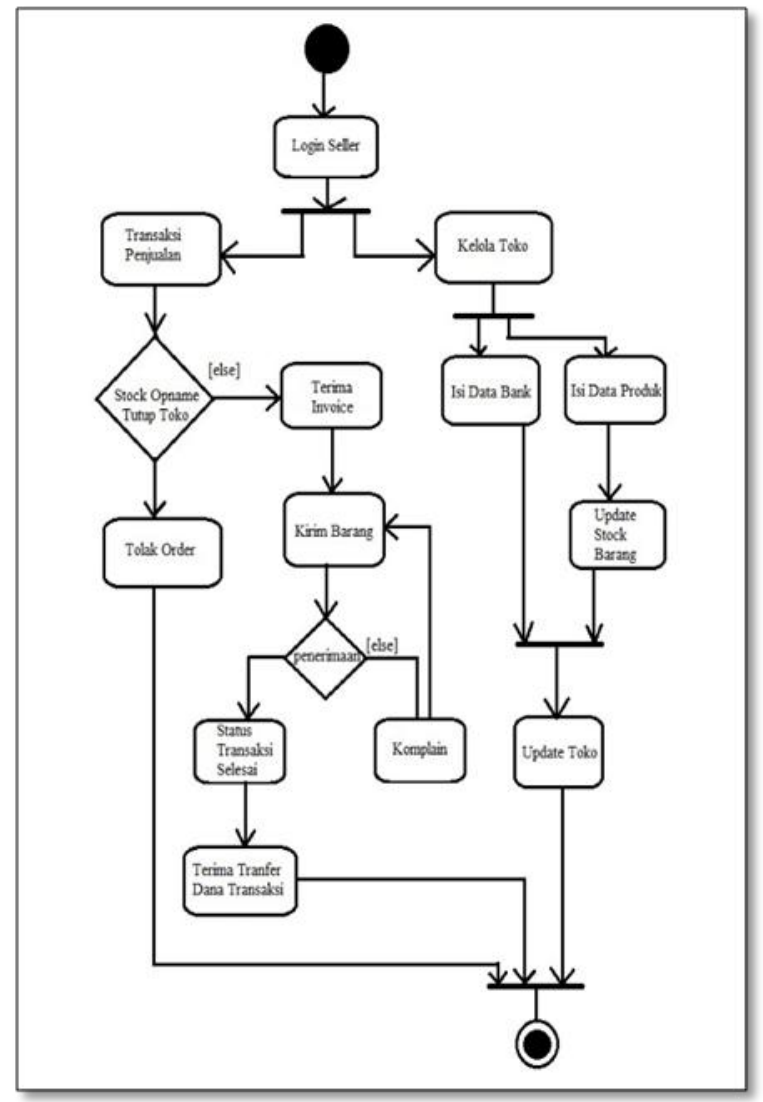

Gambar 10. Activity Diagram Seller 


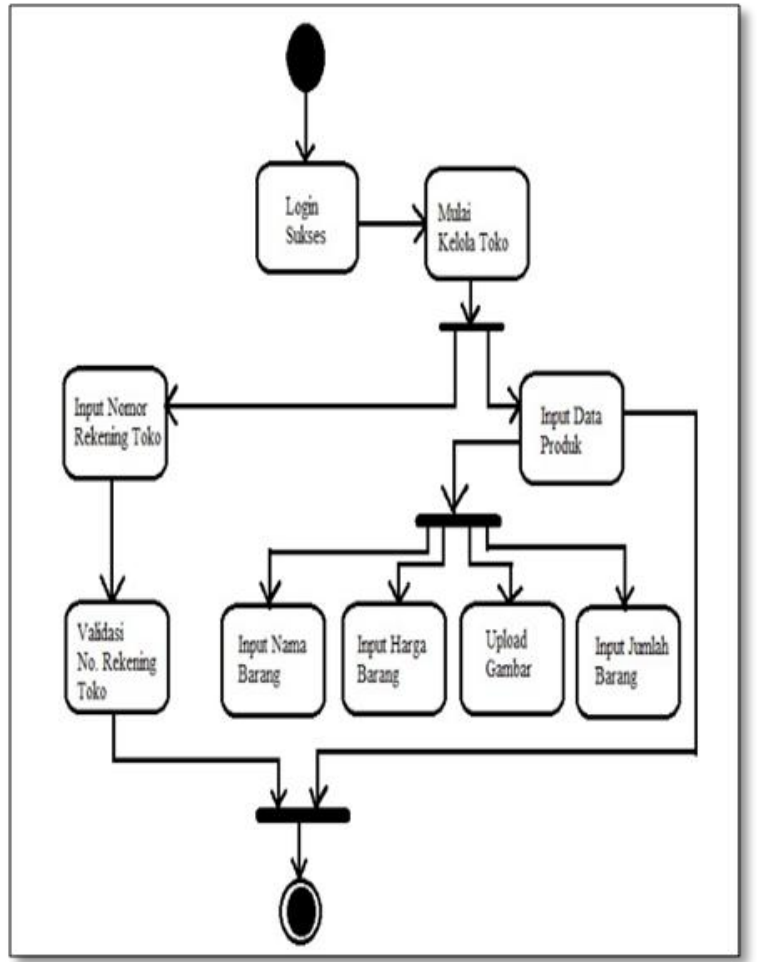

Gambar 11. Activity Diagram Kelola Toko

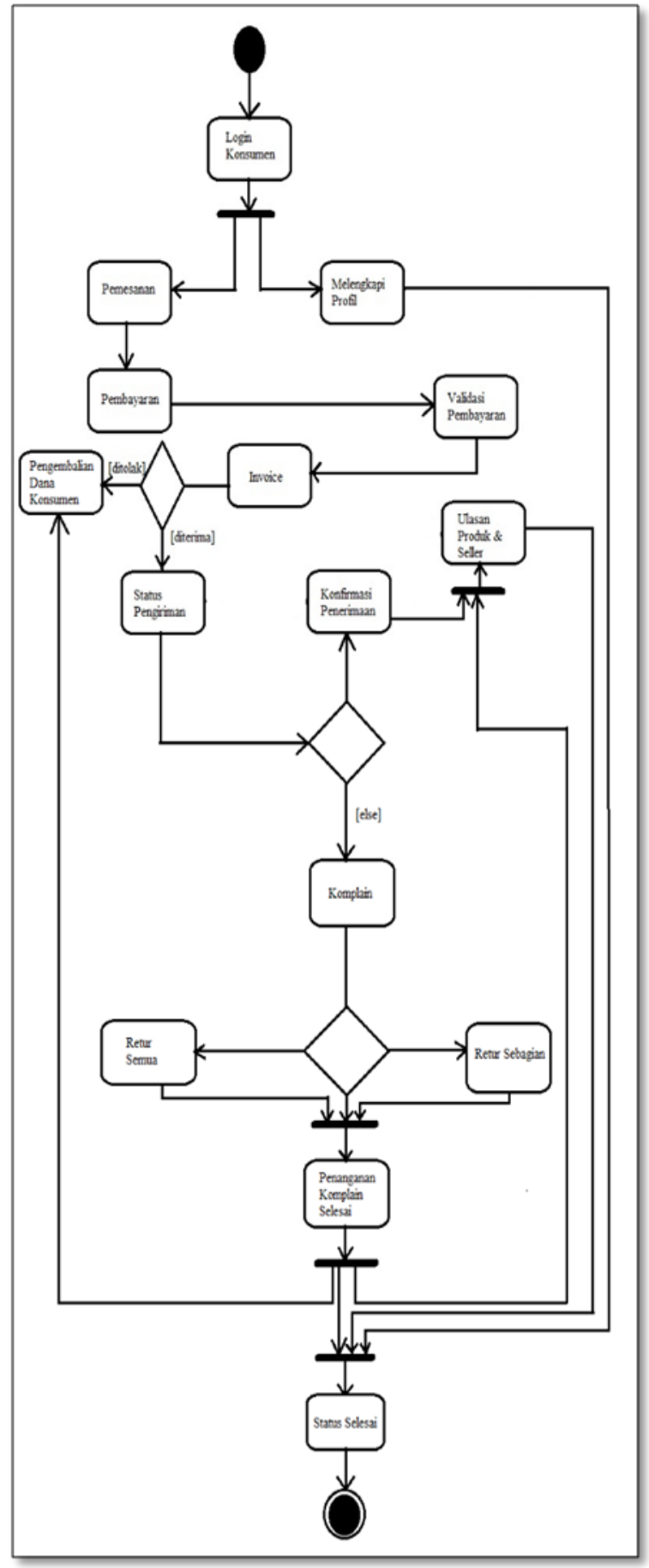

Gambar 12. Activity Diagram Konsumen 


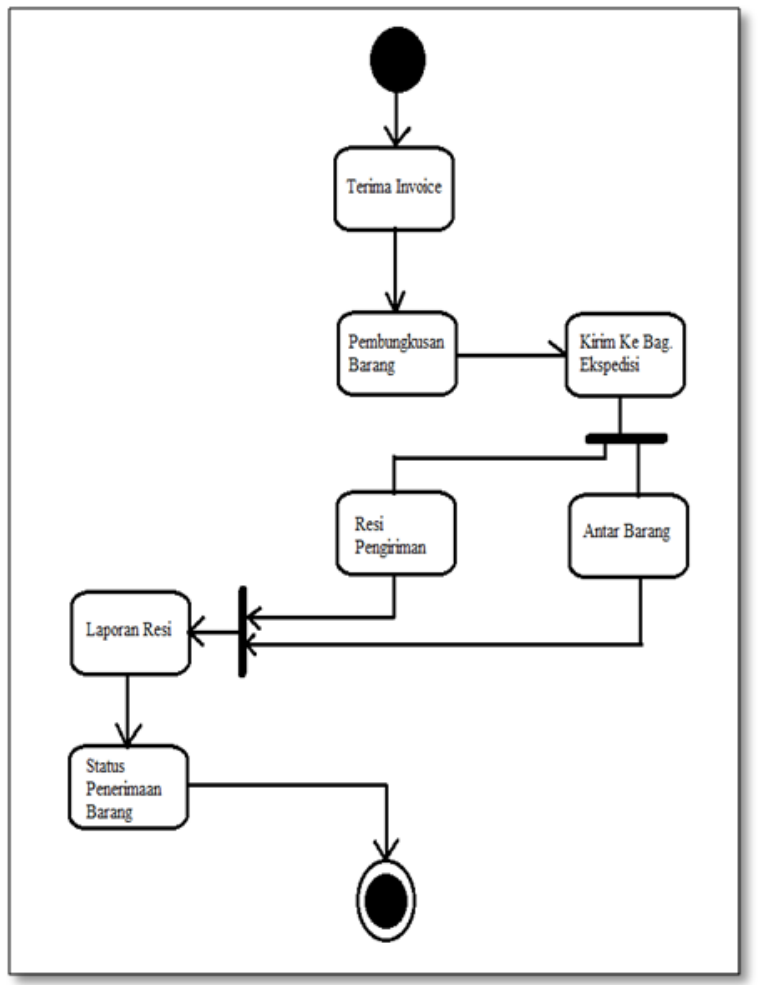

Gambar 13. Activity Diagram Pengiriman Barang

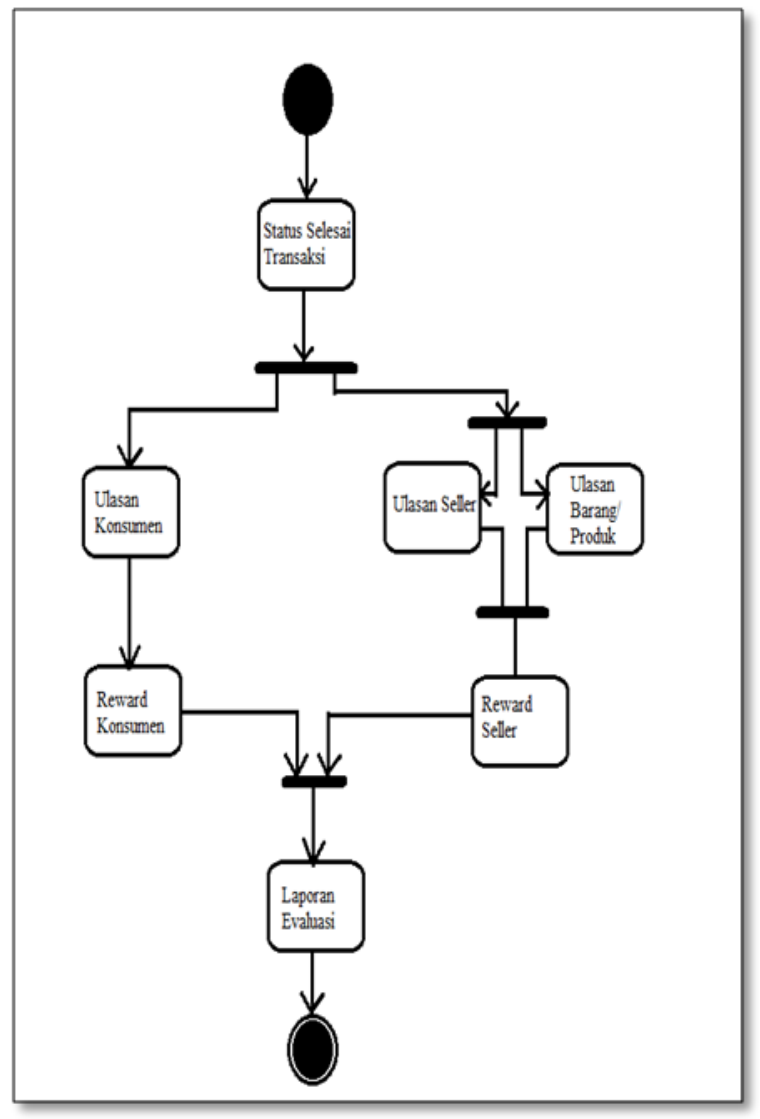

Gambar 14. Activity Diagram Ulasan
D. Diagram Hubungan Entitas

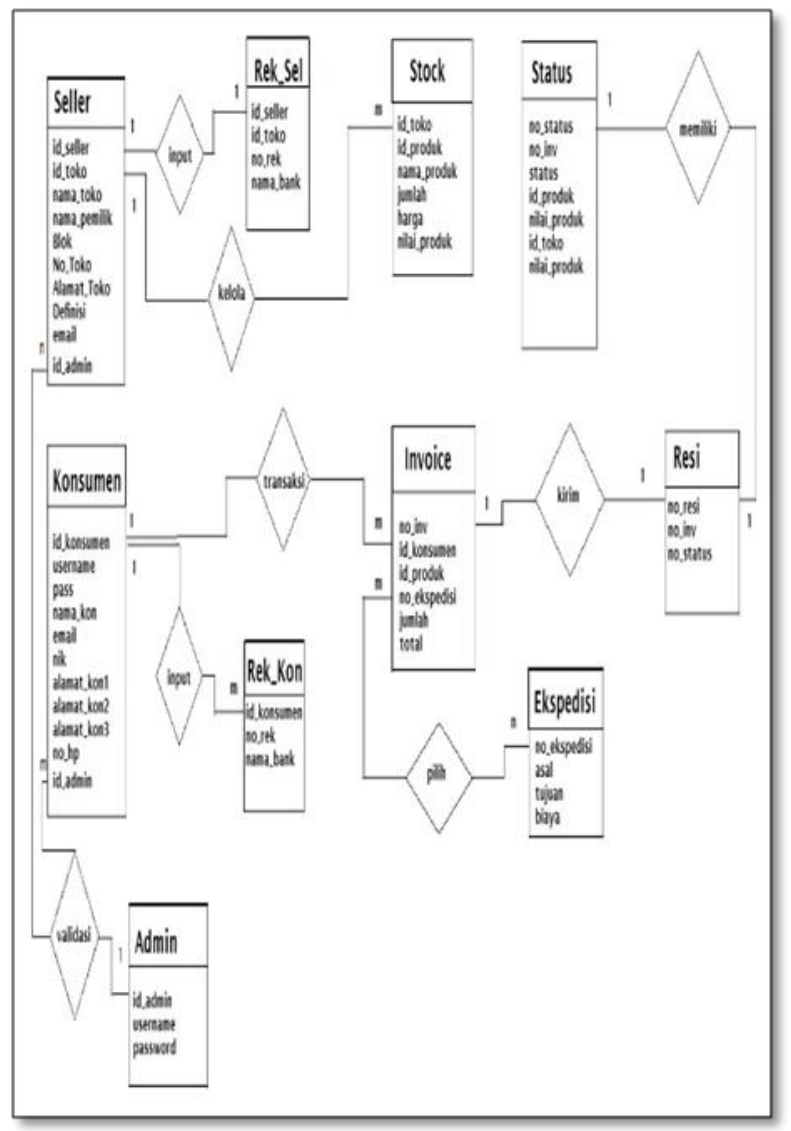

Gambar 15. Diagram Hubungan Entitas

\section{SIMPULAN}

Hasil analisis Online Market System dengan menggunakan UML ini diperoleh simpulan yaitu:

1. Sistem online market pada Pasar Tanah Abang yang efektif khusunya pada Blok $F$ sehingga transaksi penjualan secara online dapat memudahkan konsumen yang berasal dari luar daerah tanpa harus datang ke Pasar Tanah Abang.

2. Analisis sistem online market dalam bentuk UML memudahkan proses perancangan sistem online market ke tahap selanjutnya seperti perancangan Aplikasi dan Manajemen Sistem Informasi.

3. Analisis sistem online market diharapkan dapat dikembangkan dan diterapkan secara nyata kedalam 
Tenabangmarket.com sehingga dapat menjadi salah satu solusi dari permasalahan yang terjadi di Pasar Tanah Abang yaitu mengurangi kemacetan.

4. Hasil analisis Sistem Online Market Blok F Tanah Abang dapat menjadi dasar pembentukan awal sebuah manajemen baru untuk mengelola pasar secara online tanpa menghapus sistem konvensional.

\section{DAFTAR PUSTAKA}

[1] C. Jinling, S. Tong, L. Chuncan, and S. Tao, "Modeling E-Commerce Website Quality with Quality Function Deployment," 2009 IEEE Int. Conf. E-bus. Eng., 2009.

[2] H. Saragih and R. Ramdhany, "Pengaruh Intensi Pelanggan dalam Berbelanja Online Kembali melalui Teknologi Informasi Forum Jual Beli (FJB) Kaskus," J. Inf. Syst., 2012.

[3] X. Lu, L. Ye, C. Yang, and J. Yu, "Embedded XML data exchange for asynchronous communication between e-commerce systems," in 2009 International Conference on Management of e-Commerce and $e$ Government, ICMeCG 2009, 2009.
[4] P. Jiang and B. Rosenbloom, "Customer intention to return online: Price perception, attributelevel performance, and satisfaction unfolding over time," Eur. J. Mark., 2005.

[5] J. Shen, "User Acceptance of Social Shopping Sites: A Research Proposal," 12th Pacific Asia Conf. Inf. Syst. (Pacis 2008), 2008.

[6] U. Hasanah, "Sistem Informasi Penjualan Online pada Toko Suncom Pacitan," IJNS - Indones. J. Netw. Secur., 2013.

[7] A. Meida and J. Jauhari, "Aplikasi M-Commerce Untuk Penjualan Buku Pada Suatu Toko Buku Berbasis WAP (Wireless Application Protocol) Service Dengan Media Handphone.," J. Sist. Inf., 2011.

[8] J. Jauhari, "Upaya Pengembangan Usaha Kecil Menengah (UKM) Dengan Memanfaatkan ECommerce," J. Sist. Inf., 2010.

[9] A. Primawati, "Analisis Rancangan Antarmuka Aplikasi Sistem Manajemen Properti Pada Pt. Xyz," vol. 1, no. 2, pp. 193-202, 2016. 